\title{
SMART METER PARAMETERS FOR SMART GRID
}

\author{
Janardhana $S^{1}$, M S Shashikala ${ }^{2}$ \\ ${ }^{1}$ Research Scholar, Department E\&EE, SJCE Mysuru, Karnataka, India \\ shreejanardhana@gmail.com \\ ${ }^{2}$ Professor, Department E\&EE, SJCE Mysuru, Karnataka, India \\ dr.mss1962@gmail.com
}

\begin{abstract}
This paper represents the smart meter parameters from various agencies and manufacturers, which are in the field of manufacturing, standardization, and will be backbone support towards Smart Grid. These parameters are capable of manufacturing and also quoted specifications in the manufacturers brochures and documents. Here we consider to show the required specifications and standards going to be used for the smart meter for the smart grid environment. These meters shall conform to minimum mentioned specifications and standards, which can be an emerging parameter used to the practical scenario of smart meters for the smart grid applications. So this paper support the parameters to look out for smart meter technical specification and test conditions for the meter that can be able to conform to the performance standard, hence conform before the meter procurement.
\end{abstract}

Keywords: Smart Meter; Parameters; Specs; Ratings; Utilities; Consumers; Consumption; Electricity; Smart Grid;

\section{INTRODUCTION}

In our homes, cities, and state use electronic, electromechanical energy meter as of date, capable of recording consumed power in terms of KWh (Kilo Watt Hour), which is one unit of power consumption. The data will be recorded by Electricity boards, example: power supply Utilities, in Karnataka one of our area utility is CHESCOM, does meter-reading (recording of data) every month. These monthly reading records will be linked to power usage data software. These readings will be recorded as, steps of range in units, such as 1-49, 50-99, 100-149 units $(\mathrm{KWh})$. Likewise units of power consumption will be recorded for every household, as an individual residence, business units or industry or any usage entity. And calculate the amount to be paid by the consumer, by means of tariff with various rates for the different range of power unit usage. Then generate the electricity usage bills accordingly and will distribute the bills to the account holder, with the meter numbers as identity for their premises of usage as it may be. This type of meters as on date is one-way communication only, to record the measurements and power units by the Utility service personnel's only, without an access to the consumer or to the control centre of the utility. Or no communication to the consumer and to the utility or vice a verse electronically as on date.

Fast advancement in Technology, one need to upgrade to the new available electronic systems immediately, such advancement is happening in the metering field as well, but definitely at a certain cost. So next we need to proceed forward with new electronic meter called Smart Meter System that might replace the one which is in use for more than 50-60 years. Challenge here is how to replace the existing ones.
That means the so called Smart Meter planned to use in near future in India has to work under earlier installed meter environment and exhibit all the previous functions too.

These new Smart Meters shall be able to communicate the information in a comfortable, efficient way and also need to perform additional functions. To achieve this, the smart meter deployment will take place in step-by-step, feeder-byfeeder, area-by-area replacement manner instead of replacing all the existing meters at a time. For this we need to consider an efficient and strong specification smart meters with good verification methods.

\section{FUNCTIONAL ASPECTS OF SMART}

\section{METERS}

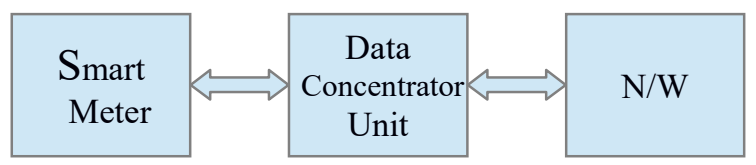

Fig 1: Smart Meter System

Some of the functional aspects of the smart meters systems should be gone through and understood. The major components of the Smart meters are Metering unit (measurement of parameters using electronics inside the meter), Load Switch(inside the meter), Metering protocol (for data exchange inside the meter), and communication modules which can be connected to Data Concentrator Unit (DCU) or for network (N/W) elements. Of these components Load switch capabilities plays a very important role. It will be inside the meter enclosures to control the flow of electricity to the Load at the instant of connect and disconnect commands as per the systems instructions. For 
single Phase two Load switches one each in phase and neutral shall be provided. Switches are to be rated to carry maximum current continuously under normal operating conditions and to withstand the switching transients during the make and the break operation. Every meter has a head end system, this system works with communication and information technology based systems situated at the top of smart metering system. It monitors and controls the smart meters and Data concentrators units, linked to smart meters data and does all tasks both from the consumer and utility point of view as per the configuration set. With these interlinking systems, the smart meter system operates for various functions, including disconnection, and reconnection operations. Disconnection mechanism of smart meters will support disconnection on varieties of conditions, such as over current, load control limit and Tamper conditions. Disconnect signal from control center flows up to meter for disconnection. Reconnection may be decided by the meter locally as per time interval and load conditions predetermined. Reconnection is also controlled by the control centre with password protection system. Connect and disconnect status of relay should be made available by the display as well as through communication system module too, whenever required.

Smart Meter System will be set as sophisticated as possible for all the electrical power control needs of utility and for the consumer needs.

Smart meters are electronic meters with added features of operations in addition to the metering function. The advantage of such smart meters are towards achieving energy efficiency system and energy conservation aspects. The introduction of pilot projects on smart metering infrastructure and then leading to smart grid, are government initiatives with Power grid corporation as consultants. The Indian standards committee has issued a draft mandate for smart meter specification. Using all these standards, meter measurement trustfulness can be achieved. This can be determined by reference measurements and also by another method called reference device (standard device). The verification for validity of the smart meters are done by removing the meters and subjecting it to an inspection in the approved laboratories. This leads to lot of expenses in logistic and is cumbersome. For ease of operation, simple remote calibration with secured data communication can be efficiently done using the modern smart meter systems. This will reduce the logistic problems and confusions, ambiguities in handling the large quantities of Smart Meters for validation over a period of time. Verification Validations can be done to minimize the economical aspects by making use of sample inspection methods. For this, specific lot size need to be predetermined by considering few factors, Such as - type of manufacturers, model of the meters, from to serial numbers, year of manufacturing, batch codes, date code, class of accuracy, type of earlier approval, making and dispatch dates, date of initial test or subsequent tests and calibrations details. Therefore the parameter's for applications and specifications plays a vital role in the selections of smart meters from various manufacturers locally as well as from abroad. If these meters satisfy the specifications and parameters of operation with all the relevant corresponding standards, such meters can be approved by the corresponding agencies for the Installation by the electrical utilities of any country for that matter. The manufacturers of smart meter system should be able to give the guarantee for the usage life and shelf life of the meters for the future purposes. They need to mention the calibration cycle and inspection cycle for the meters supplied by any vendors.

\begin{tabular}{|c|c|}
\hline \multicolumn{2}{|c|}{ FUNCTIONAL ACTIONS } \\
\hline UTILITY SIDE & CONSUMER SIDE \\
\hline $\begin{array}{c}\text { Monitor the meter } \\
\text { performance }\end{array}$ & Display can be connected \\
\hline $\begin{array}{c}\text { Remote operation of load- } \\
\text { switch }\end{array}$ & $\begin{array}{c}\text { Local option for } \\
\text { connection }\end{array}$ \\
\hline $\begin{array}{c}\text { Timely tariff with trigger } \\
\text { actions }\end{array}$ & $\begin{array}{c}\text { Control consumption per } \\
\text { utility instructions }\end{array}$ \\
\hline $\begin{array}{c}\text { Load disconnection as per } \\
\text { utility }\end{array}$ & $\begin{array}{c}\text { Request can be attended by } \\
\text { utility faster }\end{array}$ \\
\hline
\end{tabular}

\section{GENERAL PARAMETERS FOR THE SINGLE PHASE SMART METERS}

The parameter's for smart meter as per manufacturers and as per drafts and standards are as follows,

Smart meter is an AC static watt-hour meter with time of use registers, internal connect and disconnect switches with two way communication capability. It is designed to measure flow of energy, store and communicate these measurements along with other parameters defined by the following mentioned standards. It can be remotely accessed for data programming and load switch, there by enabling the deployment or support for the consideration of Smart Metering infrastructure installation works.

Single Phase Direct connection,

1. Accuracy class -2 or 1

2.Current ratings

a. Basic current: $\mathrm{I}_{\mathrm{b}}=2.5,5$ or $10 \mathrm{~A}$

b. Max current: $I_{\max }=10,20,30 \mathrm{~A}$

c. Min Current: $\mathrm{I}_{\min }=0.05 \mathrm{Ib}$

d. starting Current: $<0.004 \mathrm{Ib}$

3. Voltage Ratings

a. Reference Voltage: $V_{\text {ref }}=220,230,240 \mathrm{~V}$

Tolerance $=-40 \%$ to $+20 \%$ of $\mathrm{V}_{\text {ref }}$

4. Frequency Ratings

a. $50 \mathrm{~Hz}+/-5 \%$ at ref Temp: $27^{\circ} \mathrm{C}$ 
5. Power consumption

a. Voltage circuit $=\leq 10 \mathrm{VA}, 1.5 \mathrm{~W} / 8 \mathrm{VA}$

b. Current circuit $=\leq 4 \mathrm{VA} / 1 \mathrm{VA}$ or $0.16 \mathrm{VA}$

6. Temperature Rating

a. operating temp range $=-25^{\circ} \mathrm{C} \ldots \ldots+60^{\circ} \mathrm{C}$,

b. storing temp range $=-40^{\circ} \mathrm{C} \ldots \ldots+85^{\circ} \mathrm{C}$

7. Dielectric Strength: $4 \mathrm{KV}, 50 \mathrm{~Hz}, 1 \mathrm{~min}$

8. Communication:

In built Modules may be having

a. RF port

b. optical port

c. Infra Red (IR)

d. RS 232 or 485 as per requirements.

To support the above PARAMETERS, the general requirements and specific requirements shall follow the following STANDARDS for their specific needs.

The reference standards are,

(a) IS13779, (b) IS15959, (c) IS15884, (d) IEEE 802.15.4

(e) IEEE1901 (f) IS12346 (g) IEC-62052-11 (h) IEC-62053-

21 (j)CBIP-NO304 and also all the recent amendments if any can also be looked into while selecting a standard electronic smart energy meter for two way communications to suit our field requirements.

Here we mentioned the few specifications of the Single Phase direct connected meter. For three phase, LT meter requirement specifications and parameters lot more need to be considered.

\section{SMART METER TESTS AND CONDITIONS}

To support the mentioned PARAMETERS, following tests are conducted as per the standards to make sure the Meters are able to perform the function with the selected parameters for operation.

These tests are as per standard IS13779; IS15884

Type of tests as follows,

Test of Insulation properties - clause 9.5 of IS 13779

Impulse Voltage test ac High voltage test Insulation test

Test of Electrical parameters - IS 13779, IS15884 power consumption test

Influence of supply voltage

Influence of short-time over currents

Influence of self-heating

Influence of Heating

Influence of immunity to earth fault

Test of Accuracy -- clause 11 to 11.7 of IS 13779 Limits of error Test result interpretation

Meter constant test

Starting condition test

No-load condition Test

Ambient temperature influence test

Repeatability of error test

Test of influence quantities
Test electromagnetic compatibility-- clause 4.5 of IS 15884

Immunity to electromagnetic $\mathrm{HF}$ field

Immunity to electrostatic discharge

Fast transient burst out

Radio Interference measurement

Test for Mechanical stress - clause 12.3 of IS 13779

Vibration test

Shock test

Spring hammer test

Protection against penetration of dust and water

Resistance to heat and fire test

Test of Climatic influences - clause 8 of IS 13779

Damp heat cyclic test

Dry heat test

Cold test

Test for load switch- clause 4.6.6.2 IS15884

Done separate sample unit

Test for communication technology - IS15959

Test for association

Data Read test

Profile Read test

Selective access

Interval data

Selective programmable

Reporting of Events

Connect/ Disconnect

Data Integrity

Performance test

Stress Test

All the above tests are some of the nominal tests given. Over and above many more tests can be added if any new field problems or requirements are experienced over a period of time or future new requirements can be included in the specs, all should balance the needs and economy of the test for all the meters. Also there is an options for the utility that if any requirement changes, for the future batches of smart meter supplies, as and when required by the utility, can be incorporated before the placement of Smart Meters purchase Order to the Meter suppliers.

\section{CONCLUSION}

Highlighted parameters and test methods are used in the application of smart meter selection system for smart grid.

This paper has given the idea for smart meter parameters for the implementation of infrastructure for future smart grid.

This paper also given the information about the Performance test conditions and its corresponding standards for smart meter. Here important thing to note about is the load switch avaiability and its type of incorporation. Another important point to note is that the communication Technology capapbility of a smart meter and its trade off with the cost for the application type.

\section{ACKNOWLEDGMENT}

I thank professors of various colleges and in particularly my supervisor, Last but not the least I thank my family for their moral support and encouragement in my work. 


\section{REFERENCES}

[1] Petr Mlynek, Jiri Misurec, Martin Kounty,"Modelling and evaluation of power line for smart grid communication," Przeglad Electrotechniczny, ISSN 0033-2097, R. 87 NR 8/2011

[2] Almeroth T, Kuhn O, LinB G, lemke A, Jurgen K, "Life time prediction of smart meters," Joint international IMEKO TCI+ TC7+ TC13 symposium, August 31st September $2^{\text {nd }}, 2011$ Jena, Germany

[3] K Kok, et al.,"Field testing of smart houses for a smart grid," $21^{\text {st }}$ International conference on electricity distribution, paper 1291, Frankfurt, 6-9 June 2011,

[4] ICSA(India)Limited, cyberbad, Hyderabad,-“'Smart energy meter"- brochure.

[5] ELSEWEDY,'Energy measurement and management Meter division,"brochure.

[6] EDMI - NC 30, "Single phase multi-Tariff ANSI Meter",brochure.

[7] Working Committee Draft, "ac Static Watt hour Smart meter direct connected class I and 2," - Working Committee Draft Indian standard 11Feb-15

[8] Smart Meters and Smart Meter System, "A Metering Industry Perspective,"A Joint project of the EEI-AEIC Meter committees, March 2011.

[9] Ali Ipakchi, Farrokh Albuyeh, "Grid of the Future," IEEE Power \& Energy, Volume 7, No.2, March/April 2009.

[10]A. Clark, C.J. Pavlov ski, "Wireless Networks for the Smart Energy Grid: Application Aware Networks," IMECS 2010, vol II, March 17-19, 2010, Hong Kong.

[11]Hao- Tian Zhang, Loi-Lei Lai, "Monitoring system for smart grid," Machine Learning and Cybernetics (ICMLC), 2012 International Conference on, On Page(S) 1030-1037 vol. 3, 15-17 July 2012.

[12] Mukhopadyay P, Chawla H K, "Advances in energy conversion Technologies (ICAECT), 2014 International Conference on Digital object publication year 2014, Page(s): $77-82$.

[13] J. Jin, J. Gubbi, S Marusic and M Palaniswamy, "An Information Frame work for Creating a Smart City internet of Things", IEEE IOT Journal, Vol.1. No.2 April 2014.

[14] Chun-Hao Lo, Ansari N, "Alleviating Solar Energy Congestion in the Distribution Grid via Smart Metering Communications," Parallel and Distributed Systems, IEEE Transactions on, On page(s): 1607 - 1620 vol.23, Issue: 9, Sept.2012.

[15] Petinrin, JO, Shaaban, M. "Smart Power grid: Technologies and applications," Power and Energy (PEcon), 2012 IEEE International Conference on, On page (s): $892-897$.

[16] Andreas Wagner, Sebastian Speiser, Andreas Harth, "Semantic Web Technologies for a Smart Energy Grid: Requirements and Challenges", ISWC2010, November 2010.

[17] Ali Ipakchi, KEMA Inc, "Implementing the smart grid: Enterprise information Integration," Grid wise GridInterop Forum 2007.

\section{BIOGRAPHIES}

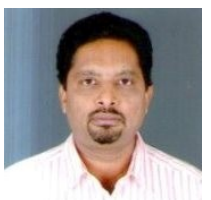

S Janardhana, BE, ME (Management), is currently Research Scholar in the department of Electrical and Electronics Engineering, Sri Jayachamarajendra College of Engineering, Mysore, under Vishweshwaraiah technological university. His area of research interests are Smart Grid systems, Smart Metering, Energy management, and communication technologies for energy utility conservation.

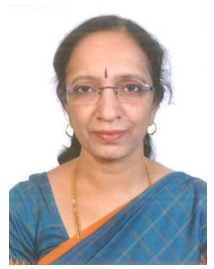

Dr. M S Shashikala, BE, Msc (Engg), Ph. $\mathrm{D}$ is currently working as a professor in the department of Electrical and Electronics Engineering, Sri Jayachamarajendra College of Engineering, Mysore. Her area of research and interests are Power system analysis, Demand Side Management, Smart Grid, Renewable energy, Micro Grid, Distribution system and Energy conservation. She has many publications in the area of demand side management. 